\title{
Normal penetration of rabbit spermatozoa through a trypsin- and acrosin-resistant zona pellucida
}

\author{
J. M. Bedford and N. L. Cross* \\ Departments of Obstetrics and Gynecology and Anatomy, Cornell University Medical College, \\ 1300 York Avenue, New York, New York 10021, U.S.A.
}

\begin{abstract}
Summary. Exposure of rabbit ova to wheat germ agglutinin (WGA) at a concentration of $50 \mu \mathrm{g} / \mathrm{ml}$ for $30-45 \mathrm{~min}$ rendered the zona pellucida at least 10 times more resistant to digestion by $1 \mathrm{mg}$ trypsin/ml, and also more resistant to acrosin. Nevertheless, the zonas of WGA-treated eggs were penetrated by spermatozoa as readily as those of untreated eggs in the same oviduct. These results suggest that penetration of spermatozoa through the zona pellucida may not require the agency of a trypsin-like enzyme acting as a primary zona lysin. The validity of the general belief that a lysin is necessary for zona penetration is considered briefly in relation to the mode of penetration and structural organization of the mammalian sperm head.
\end{abstract}

\section{Introduction}

In most mammals studied, fertilization involves passage of the spermatozoon through the cellular investment of cumulus oophorus and corona radiata, and then through the acellular zona pellucida to reach the plasma membrane of the ovum. The rostral location of the enzyme-filled acrosome on the sperm head is suggestive of a lytic function in fertilization, and sperm penetration into the egg has long been believed to depend on acrosomal enzymes. Penetration of the cellular vestment has reasonably been assumed to be mediated by acrosomal hyaluronidase, and that of the zona pellucida by a zona lysin now generally believed to be acrosin-a trypsin-like enzyme also present in the acrosome. Although the concept of a zona lysin was formulated when it was believed that the acrosome content is dispersed as the spermatozoon traverses the zona pellucida, the ultrastructural demonstration that the content of the acrosome is lost before zona penetration begins (Bedford, 1968) has not seriously shaken this idea. Both the remaining equatorial segment (Yanagimachi \& Noda, 1970) and the surface of the persisting inner membrane of the acrosome (Bedford, 1968) have been suggested as possible sites for a residual lysin.

The idea that acrosin is a lysin involved in the penetration of the zona pellucida by mammalian spermatozoa is founded primarily on reports that: (1) fertilization of rabbit eggs in vivo (Zaneveld, Robertson, Kessler \& Williams, 1971) or in vitro (Stambaugh, Brackett \& Mastroianni, 1969) was largely suppressed when capacitated spermatozoa were exposed to a relatively high concentration of trypsin inhibitor; (2) the fertilizing ability of spermatozoa was poor when the alkylating agent and trypsin inhibitor, tosyl lysine chloromethyl ketone (TLCK) was also present (Zaneveld, Robertson \& Williams, 1970); (3) trypsin-like acrosomal extracts and purified acrosin will digest the zona pellucida (Srivastava, Adams \& Hartree, 1965; Stambaugh \& Buckley, 1969; Zaneveld, Srivastava \& Williams, 1969; Polakoski \& McRorie, 1973); and (4) cytochemical reaction products in the penetration slit reflect acrosin activity there (Stambaugh, 1976).

Originally, the present study began as an effort to explore the effects of wheat germ agglutinin (WGA) treatment of rabbit eggs on their fertilizability. However, the finding that WGA markedly alters the physical properties of the zona led us to a consideration of the mechanism by which spermatozoa penetrate the zona pellucida.

\footnotetext{
* Present address: Department of Biology, University of San Diego, San Diego, California 92093, U.S.A.
} 


\section{Materials and Methods}

The general plan of the investigation involved quantitative assessment of the relative penetrability of rabbit zona pellucidas altered by WGA treatment compared with that of untreated control eggs present in the same fertilization environment.

\section{Recovery and treatments of ova}

Ovulated ova were obtained from rabbits $12 \mathrm{~h}$ after injection of 50 i.u. hCG by flushing the oviducts with medium M 199 (Gibco, New York) containing $1 \mathrm{mg}$ penicillin/ml and $1 \mathrm{mg}$ bovine testicular hyaluronidase/ml (Type VI, Sigma). After dispersal of the cumulus oophorus within a few minutes, the cells of the corona radiata were removed by shaking in 68 mM-trisodium citrate or in Tyrode's solution (Tyrode, 1910) free of divalent cations, and the eggs were then washed twice in medium M 199.

The effect of the lectin, WGA, alone on the resistance of the zona pellucida of the ovulated rabbit ovum to digestion by proteolytic enzymes was studied as follows. Eggs were incubated with WGA for 30-45 min then washed twice in medium M 199. The WGA used first, obtained from Dr P. Edelson of Rockefeller University, was highly purified but its protein concentration was unknown. It was used at a concentration, however, such that the first visible change (thinning, distortion and swelling) in the zona pellucida of the WGA-treated eggs, in $1 \mathrm{mg}$ trypsin/ml (Type III, Sigma) at $\mathrm{pH} 7.4$ in medium M 199, took at least 10 times longer than the 2-3 min required for the first signs of digestion in the zonas of untreated control ova. Subsequently, the same differential in trypsin sensitivity was obtained with a preparation of FITC-conjugated WGA obtained from Miles-Yeda, Ltd and used at a concentration of $50 \mu \mathrm{g} / \mathrm{ml}$.

An experiment was also carried out to examine whether the effects of WGA on the trypsin digestibility of the zona persisted for several hours with eggs incubated in the oviducts. Granulosa-cell denuded eggs treated with WGA $(50 \mu \mathrm{g} / \mathrm{ml}$ for $30-45 \mathrm{~min})$ were instilled into the oviducts, together with control, untreated, granulosa cell-free eggs. When recovered $3 \mathrm{~h}$ later, the WGA-treated and control eggs were washed twice in medium M 199 and then the response of the zonas in the respective groups to $0 \cdot 1 \%$ trypsin was compared.

Acrosin rather than trypsin is the enzyme presumed to facilitate zona penetration, and although biochemically similar (Stambaugh, 1974; Fritz et al., 1975) they are not identical. Therefore the relative response of the zona pellucida of untreated and WGA-treated unfertilized rabbit ova, and also of newly fertilized rabbit ova, to a solution of purified acrosin itself, containing 0.64 BAEE units $/ \mathrm{ml}$ as defined by Srivastava, Munnell, Yang and Foley (1974), was assessed as described above for trypsin.

The finding in the above tests that WGA treatment increased the resistance of the zona pellucida to proteases made it of interest finally to establish whether this effect was expressed because of a surface coating or as a consequence of a change in the character of the zonal substance throughout its thickness. To establish this, the zonas of washed WGA-treated eggs were removed by physical dissection, and half-zonas were exposed to $0.1 \%$ trypsin in the normal way. The pattern of their dissolution (i.e. whether the inner surface of the zona dissolved rapidly leaving a surface shell, or whether the dissolution occurred at a similar rate at the inner and outer surfaces) was then observed closely in a phase-contrast microscope over the next $2 \mathrm{~h}$.

\section{Penetrability of the zona pellucida}

The effect of the WGA treatment on the penetrability of the zona pellucida was evaluated as follows. Spermatozoa were obtained from New Zealand White rabbits ejaculating into an artificial vagina, or were released directly from the cauda epididymidis. The spermatozoa were suspended in medium M 199 containing $1 \mathrm{mg}$ penicillin/ $\mathrm{ml}$. A volume of $0.05 \mathrm{ml}$ of the sperm suspension containing $0.36-8.7 \times 10^{6}$ spermatozoa was introduced via a flank incision through the tubal ostium to the ampulla of a recipient doe. For each experiment, between 12 and 25 eggs obtained from 2 rabbits $12 \mathrm{~h}$ after injection of 50 i.u. hCG were treated with WGA as described above, or remained untreated, thereby serving as controls. In Trials $1-5$ performed with purified WGA obtained from Dr P. Edelson, the control eggs were treated for $10 \mathrm{~min}$ with a $\mathbf{0 . 0 2} \%$ solution of fluorescein-isothiocyanate (FITC) 
a marker which does not alter their penetrability (Overstreet, 1973), to allow their identification on recovery from the oviduct. In Trials $6-9$ the use of FITC-conjugated WGA permitted identification of the treated population of ova.

After treatment with WGA and washing twice in medium M 199, the experimental eggs, mixed with an approximately equal number of control eggs, were instilled via the flank incision into the tubal ampulla of a female inseminated 13-14 h earlier. The mixed population of eggs was recovered 4-5 h later by flushing the oviducts with medium M 199 containing penicillin, and the ova were assigned to their respective groups according to the presence of the fluorescent marker. After mounting on a slide beneath a wax-supported coverslip, each ovum was examined for the number of spermatozoa which had penetrated to the perivitelline space and, after fixation in acetic alcohol and staining in $1 \%$ lacmoid, for evidence of fertilization. Eggs were scored as penetrated if there was evidence that spermatozoa had crossed the zona, i.e. if there were perivitelline spermatozoa, or if the egg was fertilized.

\section{Results}

The zona pellucidas of eggs treated with WGA took at least 10 times longer than those of untreated controls to show the first signs of tryptic digestion, and for final dissolution (Pl. 1, Figs 1 and 2). The zona of the normal ovum collected 12-13 h after hCG and denuded of its investing cells usually began to respond by distortion, thinning and swelling after only 2-3 min, and its final disappearance occurred after about $20 \mathrm{~min}$, although occasionally a thin rim of the zona remained for up to $50 \mathrm{~min}$. By contrast, the WGA-treated egg usually displayed no response to trypsin at 20-30 min and even at $40 \mathrm{~min}$ (Pl. 1, Fig. 2) only slight and superficial change had occurred in the zona pellucida. The time of final dissolution of the WGA-treated egg was variable but this rarely occurred before $6 \mathrm{~h}$. Observation of isolated half-zonas in trypsin revealed no tendency for a more rapid digestion at the inner than the outer surface of the zona, suggesting that the enhanced resistance induced by WGA treatment was exerted throughout the thickness of the zona pellucida and did not merely reflect the presence of a surface coat. Unexpectedly, residence of granulosa cell-free eggs in the oviduct for $3 \mathrm{~h}$ elicited a distinctly greater resistance to trypsin (about 10 times greater) in the untreated and WGA-treated eggs compared with their counterparts incubated in vitro. However, the zonas of untreated eggs recovered after $3 \mathrm{~h}$ in the oviduct still disappeared completely within $100 \mathrm{~min}$ in $0.1 \%$ trypsin (Pl. 1 , Fig.

Table 1. A comparison in individual experiments with rabbits of penetration, fertilization, and numbers of perivitelline spermatozoa in groups of control and WGA-treated (i.e. zona $\geqslant 10$ times more resistant to trypsin) ova resident together in the ampulla for $4-5 \mathrm{~h}$

\begin{tabular}{|c|c|c|c|c|c|c|c|c|}
\hline \multirow[b]{2}{*}{ Exp. } & \multicolumn{4}{|c|}{ Control eggs } & \multicolumn{4}{|c|}{ WGA-treated eggs } \\
\hline & $\begin{array}{c}\text { Total } \\
\text { no. }\end{array}$ & Penetrated* & Fertilized $\dagger$ & $\begin{array}{c}\text { Perivitelline } \\
\text { sperm. } \\
\text { (mean } \pm \text { s.e.m.) }\end{array}$ & $\begin{array}{c}\text { Total } \\
\text { no. }\end{array}$ & Penetrated ${ }^{*}$ & Fertilized $\dagger$ & $\begin{array}{c}\text { Perivitelline } \\
\text { sperm. } \\
\text { (mean } \pm \text { s.e.m.) }\end{array}$ \\
\hline 1 & 6 & 6 & 6 & $7 \cdot 0 \pm 2 \cdot 7$ & 6 & 5 & 4 & $4 \cdot 8 \pm 2 \cdot 4$ \\
\hline 2 & 5 & 5 & 5 & $0.8 \pm 2.7$ & 5 & 4 & 4 & $0.4 \pm 0.2$ \\
\hline 3 & 4 & 4 & 4 & $3 \cdot 0 \pm 1 \cdot 1$ & 7 & 7 & 7 & $4.3 \pm 0.8$ \\
\hline 4 & 9 & 4 & 4 & $0.4 \pm 0.3$ & 14 & 7 & 6 & $0.2 \pm 0.2$ \\
\hline 5 & 5 & 5 & 4 & $9.0 \pm 1.8$ & 8 & 8 & 6 & $7.2 \pm 1.8$ \\
\hline 6 & 5 & 5 & 4 & $22 \cdot 8 \pm 6 \cdot 4$ & 5 & 5 & 4 & $20 \cdot 1 \pm 5 \cdot 5$ \\
\hline 7 & 4 & 3 & 3 & $1.0 \pm 0.4$ & 6 & 4 & 4 & $0.8 \pm 0.5$ \\
\hline 8 & 7 & 7 & 6 & $2.4 \pm 1.0$ & 8 & 8 & 8 & $0.9 \pm 0.3$ \\
\hline 9 & 9 & 9 & 8 & $15 \cdot 0 \pm 4 \cdot 5$ & 10 & 10 & 10 & $10.4 \pm 3.2$ \\
\hline Total & 54 & 48 & 44 & & 69 & 58 & 53 & \\
\hline
\end{tabular}

* Fertilized or with perivitelline spermatozoa.

$\dagger$ Indicated by the presence of a fertilizing sperm tail and/or a male pronucleus. 
3), whereas those exposed to WGA and then to tubal incubation for $3 \mathrm{~h}$ appeared highly resistant to subsequent challenge by trypsin, showing no change even after $100 \mathrm{~min}$ (Pl. 1, Figs 2 and 4) when the fluorescence emitted by the FITC-WGA was still very obvious within the zona. These results indicate not only that the effects of WGA on the zona pellucida persist during its incubation in the oviduct, but that the trypsin-resistance of the zona pellucida of untreated and WGA-treated eggs is greatly enhanced by the oviductal environment itself. Although the effects appeared more slowly, presumably because of the much weaker specific activity of the preparation of acrosin used, the findings with acrosin were similar in principle to those obtained with trypsin. The acrosin preparation brought about a gross swelling and thinning of the zonas of control unfertilized eggs after $6 \mathrm{~h}$ at $37^{\circ} \mathrm{C}$, whereas those of washed eggs first treated with $50 \mu \mathrm{g} \mathrm{WGA} / \mathrm{ml}$, or of eggs recently fertilized, were visibly unchanged even by $6 \mathrm{~h}$.

Although WGA at $50 \mu \mathrm{g} / \mathrm{ml}$ or concentrations equivalent to it greatly increased the resistance of the zona pellucida to the action of trypsin and acrosin, prior exposure of rabbit eggs to this concentration of WGA did not prevent or even reduce sperm penetration through the zona (Table 1): none of the differences between the control and WGA-treated eggs was significant $(P>0.1$ : Student's $t$ test).

\section{Discussion}

The observation that the acrosome content is lost before zona penetration (Bedford, 1968) has not really altered the view that a lytic enzyme is a key factor in this phase of fertilization. It is now considered that sufficient lysin remains bound to the sperm head after the reacted acrosomal elements have been shed, and the demonstration that the equatorial segment of the hamster spermatozoon is not required to vesiculate for successful zona penetration (Moore \& Bedford, 1978) supports the contention from studies of the rabbit (Bedford 1968, 1972), that the inner membrane of the acrosome is the most likely site of this zona lysin. In accord with this, biochemical findings suggest that a significant complement of acrosin does remain bound to this membrane after disruption of the acrosome (Brown, Andani \& Hartree, 1975). The results of the present experiments, however, raise doubts about the concept of acrosin as the zona lysin and perhaps even about the general idea that acrosomal hydrolases are critical for zona penetration. If acrosin plays an essential role in the penetration of spermatozoa through the rabbit zona pellucida, it is reasonable to expect that a marked increase in the resistance of the zona to acrosin will be accompanied by a decrease in its penetrability to spermatozoa.

\section{EXPLANATION OF PLATE 1}

Fig. 1. Ovulated granulosa cell-free rabbit ovum exposed to $0 \cdot 1 \%$ trypsin at $\mathrm{pH} 7 \cdot 4$ for only 20 min at room temperature. The now-diaphanous zona pellucida has almost completely dissolved within this brief period. Phase contrast, $\times 340$.

Fig. 2. Ovulated rabbit ovum exposed to $50 \mu \mathrm{g}$ WGA $/ \mathrm{ml}$ after removal of its follicular cell investment, washed three times and incubated in $0.1 \%$ trypsin for $40 \mathrm{~min}$. Treatment with WGA significantly increased the resistance of the zona pellucida to trypsin because the external surface of the zona is only beginning, at $40 \mathrm{~min}$, to display the first signs of trypsin-induced erosion (compare with Fig. 1). Complete dissolution of the zona of the WGA-treated egg generally required $6 \mathrm{~h}$ or more. Phase contrast, $\times 340$.

Fig. 3. Untreated unfertilized rabbit ovum exposed to $0 \cdot 1 \%$ trypsin for 100 min after incubation as a granulosa cell-free ovum for $3 \mathrm{~h}$ in the oviduct. In this case the zona was not significantly altered at 20 min (see Fig. 1) and required almost $100 \mathrm{~min}$ for its dissolution because exposure to the oviduct alone renders the zonas of normal unfertilized cell-free eggs considerably more resistant to the action of trypsin. Phase contrast, $\times 340$.

Fig. 4. An unfertilized ovum exposed to $50 \mu \mathrm{g} \mathrm{WGA} / \mathrm{ml}$ for $40 \mathrm{~min}$, incubated in the oviduct for $3 \mathrm{~h}$, and then exposed for $100 \mathrm{~min}$ to $0.1 \%$ trypsin. In contrast to Figs $1-3$, there is no visible evidence of disruption of the zona pellucida by trypsin after this prolonged period. It is apparent that WGA enhancement of the trypsin-resistance of the zona pellucida persists after incubation in the oviduct (see Fig. 3) and that exposure to the environment of the oviduct further enhances the resistance induced by WGA alone (compare with Fig. 2 of a non-incubated WGA-treated egg after 40 min in trypsin). Phase contrasta $\times$ 340at 04/26/2023 05:49:37AM 
PLATE I
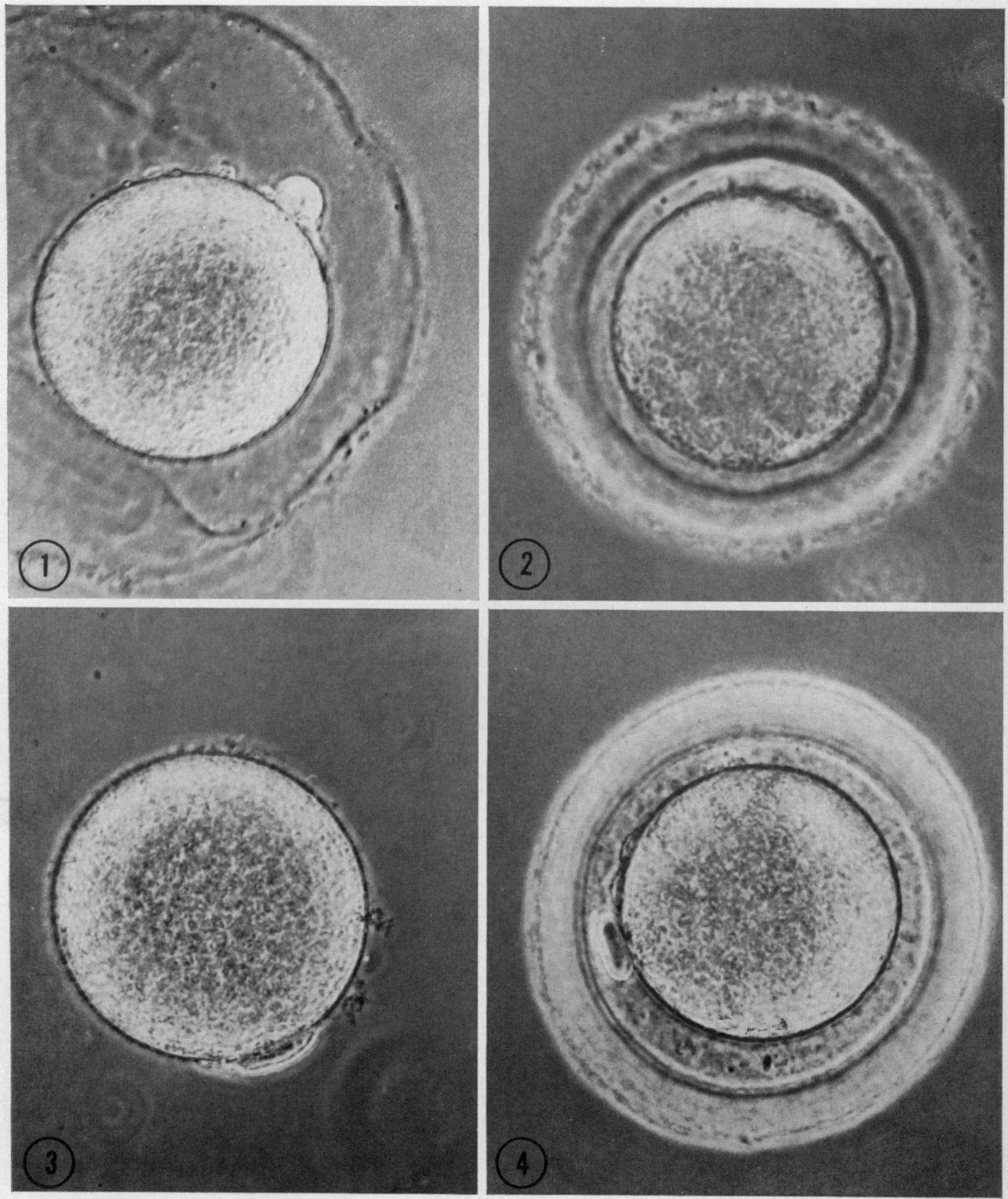
There are now two cases known in which this expectation is not fulfilled: one is the WGA treatment described here, and the other is fertilization itself. After fertilization, the rabbit zona pellucida becomes significantly more resistant to digestion by trypsin (Chang \& Hunt, 1956; Conrad, Buckley \& Stambaugh, 1971), and to acrosin (present results), and yet the zonas of previously fertilized and unfertilized rabbit eggs placed together in the same oviduct are penetrated by the same number of spermatozoa in 3-4 h (Overstreet \& Bedford, 1974). The results obtained here with WGA treatment are similar in principle, because the effects of WGA persist during oviductal incubation. Not only was the fluorescence of the FITC-WGA still clearly visible within the zona, but the differential resistance to trypsin shown by the zonas of control and WGA-treated eggs recovered from the oviduct was very obvious (see Pl. 1, Figs 3 and 4). The fact that the zonas of unfertilized control and of WGA-treated eggs were all significantly more resistant to trypsin digestion after exposure to the tubal environment alone was an unexpected finding, and cannot now be explained although further experiments are in progress in this laboratory.

Since the molecular basis of the WGA- and fertilization-induced resistance to trypsin or acrosin is not known, the fact that these changes do not retard sperm penetration through the rabbit zona pellucida cannot be construed as proving that a trypsin-like enzyme plays no part in zona penetration. The use of much higher $(200-250 \mu \mathrm{g} / \mathrm{ml})$ concentrations of WGA does cause a reduction in the number of spermatozoa in the perivitelline space of treated eggs compared to that in control eggs exposed to the same fertilization environment in vivo (unpublished results). Soluble trypsin may be a poor model for membrane-bound acrosin (Hartree, 1977). Moreover, it is possible that if there is a functional concentration of acrosin remaining on the reacted sperm head after loss of the acrosome cap, this may be greater than that of the trypsin or acrosin used here. Nonetheless, the consistent finding that a significant increase in the resistance of the zona pellucida to their action had no apparent influence on penetration does cast doubt on the idea that similar enzymes play a critical part in effecting sperm passage through the zona. In fact, the evidence favouring acrosin as the zona lysin is not compelling when examined critically (see also Morton, 1976). Although a purified preparation of acrosin can dissolve the zona pellucida (Polakoski \& McRorie, 1973), certain non-tryptic enzymes and disulphidereducing agents will also disrupt its integrity (see McRorie \& Williams, 1974). Furthermore, the existing reports that certain trypsin inhibitors reduced the fertilization rate in vivo or in vitro are difficult to evaluate in terms of physiological mechanisms, for several reasons. In some cases, interpretation of the effects of inhibitors in biological situations is not clear cut because site-specific alkylating agents such as TLCK (Zaneveld et al., 1970) are not specific for trypsin; they react with nucleophilic groups and inhibit trypsin activity because it has a histidine residue at the active site (Shaw \& Springhorn, 1967). Moreover, with some in-vivo studies checks do not appear to have been made for the presence of motile spermatozoa in the oviduct as an indicator that sperm viability had not been compromised. Also, it has not been shown that the expected number of spermatozoa were adhering to the zona pellucida of the unfertilized eggs and that the agent specifically inhibited penetration at this point. In fact, experiments conducted invivo (Zaneveld et al., 1971) or in vitro (Stambaugh et al., 1969) have utilized ova still invested by cumulus oophorus. Therefore, even if the agents had acted specifically to suppress acrosomal enzymes, inhibition could have been exerted at the level of this cellular vestment rather than at the zona. Finally, although soya bean inhibitor was used up to a concentration of $1 \mathrm{mg} / \mathrm{ml}$ by Stambaugh et al. (1969), comparable protein was not added to the controls to account for non-specific suppression which can easily be elicited in in-vitro fertilization systems. For example, the inclusion of soya bean inhibitor at $0.75 \mathrm{mg} / \mathrm{ml}$ (with a presumed $98 \%$ inhibition of acrosomal trypsin-like enzyme) allowed a fertilization rate of $35 \%$ which was comparable with the $30 \%$ and $41 \%$ obtained in the control flasks in 2 of the 4 experiments in that series (Table 2 of Stambaugh et al., 1969).

Among other evidence which seems paradoxical if acrosin is to be considered a zona lysin is the report that trypsin removes essential sperm receptors from the surface of the hamster zona pellucida, thereby rendering it impenetrable (Hartmann \& Gwatkin, 1971). It is possible that other acrosomal enzymes could contribute to the phase of zona penetration; crude acrosomal extracts appear more effective in digesting the zona than might be forecast on the basis of their acrosin content (Hartree, (1977), and the mammalian acrosome contains a variety of enzymes, including other proteinases $05: 49: 37 \mathrm{AM}$ 


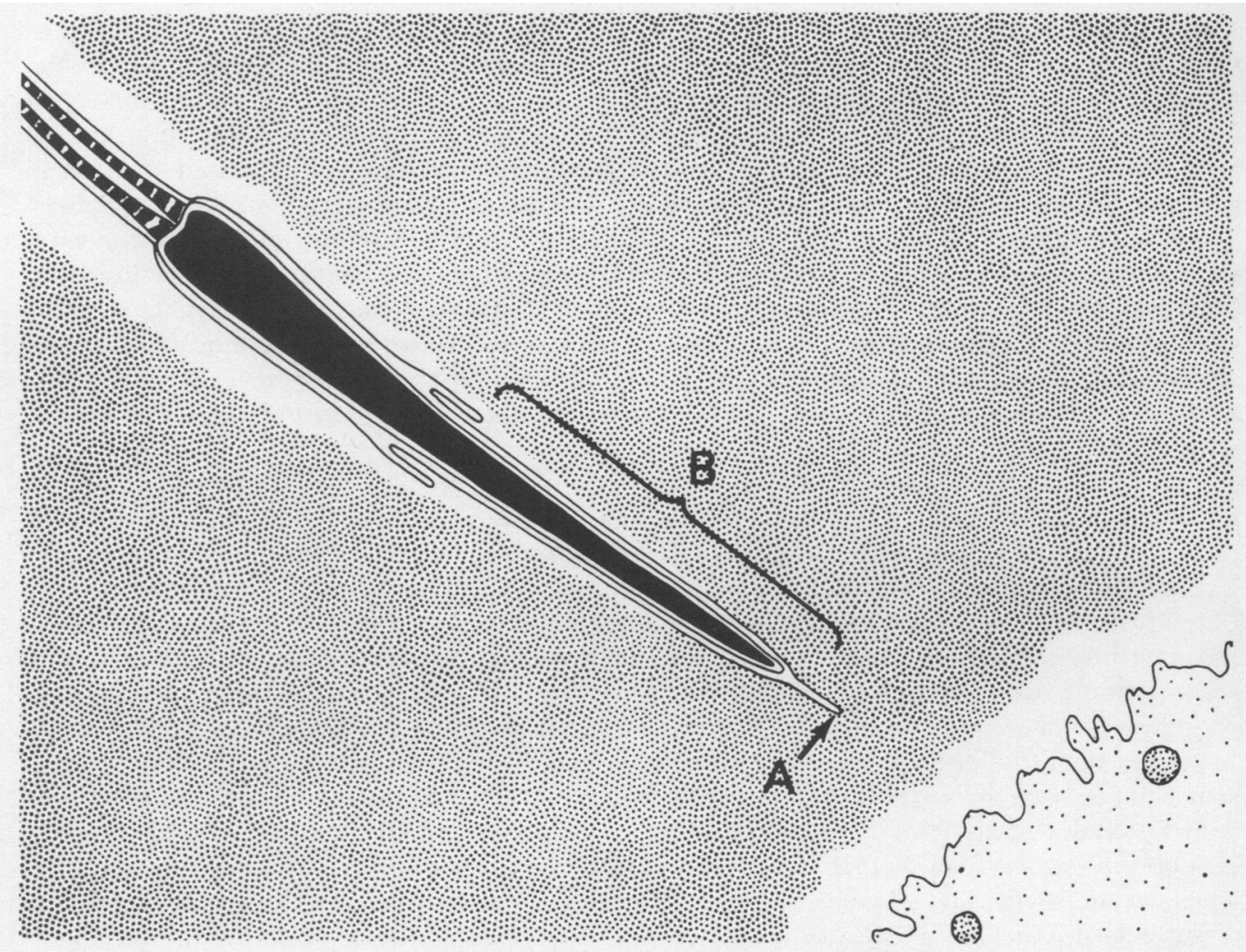

Text-fig. 1. Diagram of a sagittal section of a paddle-shaped spermatozoon, or of a hook-shaped rodent spermatozoon, as it is penetrating the zona pellucida. Within the zona pellucida, the spermatozoon approaches the ovum at an angle which varies from the tangential to the almost perpendicular. $A=$ the narrow rostral border of the perforatorium; $B=$ the lateral expanse of the inner acrosome membrane to which residual acrosin appears bound.

(Allison \& Hartree, 1970; McRorie \& Williams, 1974; McRorie, Turner, Bradford \& Williams, 1976). The notion of a hyaluronidase-proteinase complex (Stambaugh, 1972) seems unlikely, however, because in at least one insectivore, Suncus murinus, the acrosome contains acrosin but no hyaluronidase activity (J. M. Bedford, G. W. Cooper \& G. L. Dryden, unpublished observations). A role for acrosin in the acrosome reaction itself (Meizel \& Lui, 1976) or in interaction with the vitelline surface (Wolf, 1977) is also quite possible, although the validity of these suggestions must rest on the interpretation that the inhibitors acted in a specific manner on these delicate events.

There seems no doubt that acrosomal enzymes do facilitate fertilization at some stage, and the belief that the spermatozoon requires a lysin to be able to penetrate through the substance of the zona pellucida, is now widely held. This last concept might not, however, have gained such a ready acceptance had it been clear some decades ago, at the outset of investigations of mammalian sperm function, that the visible content of the acrosome is lost before zona penetration (see Text-fig. 1). It may be useful now to examine more carefully the concept that lysins play an essential role in penetration of the zona pellucida, because certain features of the eutherian spermatozoon suggest that they may not. It is clear from phase-contrast and transmission electron microscope studies that spermatozoa pass through the zona pellucida by way of a rather narrow penetration slit, the angle of which may vary from the tangential to one almost perpendicular to the vitelline surface. Viewed critically the ultrastructural image of a spermatozoon in a penetration slit within the zona (Text-fig. 1) suggests that a lysin bound to the inner acrosome membrane over the region designated $B$ would not facilitate to any extent the forward thrust of a sperm head oscillating in a plane perpendicular to that of the diagram. 
A lysin could operate effectively in that respect only at the leading border of the sperm head (A); but there is no evidence of any concentration of enzyme activity there. In fact, the apical projection of the perforatorium seen in most mammals would act to minimize the area of sperm surface rich in lysin interacting with the opposing zona substance. But the shape and the limits of distribution of the perforatorium over the head would maximize the force per unit area exerted on the zona by the leading border of the spermatozoon during its tail-mediated lateral oscillations. The importance of motive force as a key factor for penetration is suggested by the evolution in eutherian spermatozoa of an unusually intense disulphide cross-linking throughout the nucleus and perinuclear material (including perforatorium) which must render these structures more rigid (Bedford \& Calvin, 1974). Its importance seems implied also in the observation that some spermatozoa exhibit the most intense flagellar activity only when capacitated, and thus when prepared for immediate interaction with the egg (Yanagimachi, 1970).

We thank Dr P. Edelson, Rockefeller University, for the gift of wheat germ agglutinin, and Dr W. L. Williams and Dr A. Dudkiewicz, Department of Biochemistry, University of Georgia, for their help in observation of the effects of free acrosin on the zona pellucida. This study has been supported by a Fellowship to N.L.C. from the Rockefeller Foundation, by a grant from the Ford Foundation, and by NIH grant HD-07257.

\section{References}

Allison, A.C. \& Hartree, E.F. (1970) Lysosomal enzymes in the acrosome and their possible rôle in fertilization. J. Reprod. Fert. 21, 501-515.

BEDFORD, J.M. (1968) Ultrastructural changes in the sperm head during fertilization in the rabbit. $A m . J$. Anat. 123, 329-358.

BEDFORD, J.M. (1972) An electron microscopic study of sperm penetration into the rabbit egg after natural mating. Am. J. Anat. 133, 213-253.

Bedford, J.M. \& CALvin, H.I. (1974) The occurrence and possible functional significance of $-\mathrm{S}-\mathrm{S}$ - crosslinks in sperm heads, with particular reference to eutherian mammals. J. exp. Zool. 188, 137-156.

Brown, C.R., ANDANI, Z. \& Hartree, E.F. (1975) Studies on ram acrosin. Isolation from spermatozoa, activation by cations and organic solvents, and influence of cations on its reaction with inhibitors. Biochem. J. 149, 133-146.

Chang, M.C. \& Hunt, D.M. (1956) Effects of proteolytic enzymes on the zona pellucida of fertilized and unfertilized mammalian eggs. Expl Cell Res. 11, 497499.

Conrad, K., Buckley, J. \& Stambaugh, R. (1971) Studies on the nature of the block to polyspermy in rabbit ova. J. Reprod. Fert. 27, 133-135.

Fritz, H., SchleuniNG, W-D., Schiessler, H., Schill, W-B., WendT, V. \& Winkler, G. (1975) Boar, bull and human sperm acrosin-isolation, properties and biological aspects. In Proteases and Biological Control pp. 715-735. Eds E. Reich, D. B. Rifkin \& E. Shaw. Cold Spring Harbor, New York.

Hartmann, J.F. \& GWatkin, R.B.L. (1971) Alteration of sites on the mammalian sperm surface following capacitation. Nature, Lond. 234, 479-481.

HARTREE, E.F. (1977) Spermatozoa, eggs and proteinases Biochem. Soc. Trans, 5, 375-394.

MCRorie, R.A. \& Williams, W.L. (1974) Biochemistry of mammalian fertilization. A. Rev. Biochem. 43, $777-803$.
MCRorie, R.A., Turner, R.B., Bradford, M.M. \& WILliams, W.L. (1976) Acrolysin, the aminoproteinase catalysing the initial conversion of proacrosin to acrosin in mammalian fertilization. Biochem. Biophys. Res. Commun. 71, 492-498.

Meizel, S. \& Lui, C.W. (1976) Evidence for the role of a trypsin-like enzyme in the hamster sperm acrosome reaction. J. exp. Zool. 195, 137-144.

MOORE, H.D.M. \& BEDFORD, J.M. (1978) Ultrastructure of the equatorial segment of hamster spermatozoa during penetration of oocytes. J. Ultrastruct. Res. 62, 110-117.

MORTON, D.B. (1976) Lysosomal enzymes in mammalian spermatozoa. In Lysosomes in Biology and Pathology, vol. 5, pp. 203-255. Eds J. T. Dingle \& R. T. Dean. North Holland Publishing Co., Amsterdam.

Overstreet, J.W. (1973) The labelling of living rabbit ova with fluorescent dyes. J. Reprod. Fert. 32, 291294.

Overstreet, J.W. \& Bedford, J.M. (1974) Comparison of the penetrability of the egg vestments in follicular oocytes, unfertilized and fertilized ova of the rabbit. Devl Biol. 41, 185-192.

Polakoski, K. \& McRorie, R.A. (1973) Boar acrosin. II. Classification, inhibition, and specificity studies of a proteinase from sperm acrosomes. J. biol. Chem. 248, 8183-8188.

SHAw, E. \& SPRINGHORN, S. (1967) Identification of the histidine residue at the active center of trypsin labelled by TLCK. Biochem. Biophys. Res. Commun. 27, 391397.

Srivastava, P.N., Adams, C.E. \& Hartree, E.F. (1965) Enzymic action of acrosomal preparations on the rabbit ovum in vitro. $J$. Reprod. Fert. 10, 61-67.

Srivastava, P.N., Munnell, J.F., Yang, C.H. \& FoleY, D.W. (1974) Sequential release of acrosomal membranes and acrosomal enzymes of ram spermatozoa. J. Reprod. Fert. 36, 363-372.

Stambaugh, R. (1972) Acrosomal enzymes and fertili- 
zation. In Biology of Mammalian Fertilization and Implantation, pp. 166-212. Eds K. S. Moghissi \& E. S. E. Hafez. Thomas, Springfield.

Stambaugh, R. (1974) Amino acid content of rabbit acrosomal proteinase and its similarity to human trypsin. Science, N. Y. 186, 745-746.

STAMBAUGH, R. (1976) Sperm proteinase release during fertilization of rabbit ova. J. exp. Zool. 197, 121-125

Stambaugh, R. \& Buckley, J. (1969) Identification and subcellular location of the enzymes effecting penetration of the zona pellucida by rabbit spermatozoa. J. Reprod. Fert. 19, 423-432.

Stambaugh, R., Brackett, B.G. \& Mastroinni, L. (1969) Inhibition of in vitro fertilization of rabbit ova by trypsin inhibitors. Biol. Reprod. 1, 223-227.

TYRODE, M.V. (1910) The mode of action of some purgative salts. Arch. Int. Pharmacodyn. 20, 205.

WoLF, D.P. (1977) Involvement of a trypsin-like activity in sperm penetration of zona-free mouse ova. J. exp. Zool. 199, 149-156.
Yanagimachi, R. (1970) The movement of golden hamster spermatozoa before and after capacitation. J. Reprod. Fert. 23, 193-196.

YANAGIMACH, R. \& NODA, Y.D. (1970) Ultrastructural changes in the hamster sperm head during fertilization. J. Ultrastruct. Res. 31, 465-485.

Zaneveld, L.J.D., Srivastava, P.M. \& Williams, W.L. (1969) Relationship of a trypsin-like enzyme in rabbit spermatozoa to capacitation. J. Reprod. Fert. 20, 337339.

ZANEVELD, L.J.D., ROBERTSON, R.I. \& Williams, W.L. (1970) Synthetic enzyme inhibitors as antifertility agents. FEBS Letters 11, 345-347.

ZANEVELD, L.J.D., ROBERTSON, R.T., KesSleR, M. \& WILLIAMS, W.L. (1971) Inhibition of fertilization in vivo by pancreatic and seminal plasma trypsin inhibitors. J. Reprod. Fert. 25, 387-392.

Received 31 March 1978 